\title{
Exploration on the National Cultural Corridor of " Intercalary Salt Ancient Road"
}

\author{
Jian Tao \\ School of Foreign Languages, Xichang University, Xichang, Sichuan 615000,China \\ *Corresponding author. Email: taojianwin@163.com
}

\begin{abstract}
Thousands of years of production and marketing history of "well salt" in Liangshan Prefecture, Sichuan Province has contributed to the formation of " Intercalary salt ancient road" [1], which has an important impact on the regional economy and regional culture of Sichuan and Yunnan. It runs through a unique cultural line, aiming to explore the causes of "Intercalary salt ancient road", save the dying precious materials on the cultural line, and find out the distribution route of "Intercalary salt ancient road" and provide basis for the protection of " Intercalary salt ancient road".

Keywords:" Intercalary salt ancient road"; national cultural corridor; ancient town village; heritage protection

\section{INTRODUCTION}

"Salt has a very rich cultural content. Using salt as the entry point for narrative and understanding history, inquire about the rich connotation and unique cultural

important carrier of promoting economy and spreading culture. The formation of " Intercalary salt ancient road" is closely related to salt, iron and gold, which are abundant in salt source since ancient times. Because of the benefit of salt and iron, the ancient Intercalary salt road plays an important role in the transportation history of Southwest China.
\end{abstract} characteristics of salt culture, and then build salt culture." [2] Yanyuan County has a wide range of jurisdiction in history, including Jinmuli, Yanbian and other counties." "There were more than 30 kinds of tombs, such as sea mussel beads and agate, in the tombs from the Warring States period to the early Han Dynasty, unearthed in Maojiaba, Shuanghe Township in 1989. It proves that the ancient road opened as an important trunk of the Southern Silk Road as early as AD The first twelfth century."Intercalary salt ancient road " is named after Yuandi Intercalary salt prefecture (county). The name of " Intercalary salt ancient road" was first seen in the inscription of Zhu Zhen on the road. According to the Yanyuan County annals of the Qing Dynasty, during the Jiajing period of the Ming Dynasty, when Zhu Zhen, deputy inspector general, inspected the Jianchang Road, he supervised the construction of the Dachong River (Yalong River) cable bridge. Afterwards, the four characters of " Intercalary salt ancient road" were inscribed on the stone wall beside the road.The " Intercalary salt ancient road" originated from the source of Sichuan salt, which had a great impact on the intersection of Sichuan and Yunnan. It is a thousand-year-old road running through a large area between the Jinsha River and Yalong River on the edge of Sichuan and Yunnan. Walking in the mountains of the plateau, walking around the path of the mountain, the debris flow and flying rocks hit people frequently, and the branches are densely distributed, covering Xichang, Mianning, Dechang, Panzhihua, Yanyuan, Muli in Sichuan, Lijiang, Ninglang, Yongsheng, Huaping and other places in Yunnan. It refers to the ancient road from Xichang, the capital of Liangshan Prefecture, to Lijiang via Yanyuan, Ninglang. It flourished because of salt and became an

\section{ORGANIZATION OF THE TEXT}

\subsection{The cultural significance of the research on the ancient Intercalary Salt Road}

Taking the "Intercalary salt ancient road" as a clue to establish the coordinates of the historical and regional vertical axes, we can more systematically study the cultural development and interaction among different ethnic groups in this area.

Vertical axis of history: the history of " Intercalary salt ancient road" almost runs through the history of human development in this area.There are a large number of salt springs and salt wells on the exposed surface in the (YanYuan)salt source and other places."The salt rich area in the upper reaches of Jinsha River is one of the core areas for the formation of ancient Qiang culture. In the Han Dynasty[3], Kunming species were used to transport salt by livestock and herds, and to do business .In the Yuan Dynasty, black and white salt wells opened together, and the merchants "transported rice in salt, so that cattle, horses, sheep, felt, and cloth could prosper. The famous Italian tourist Marco Polo has visited here (Yanyuan) to investigate and describe the salt production and prices. "Ancient Intercalary Salt Road" was named after Yuan Zhi's Intercalary salt state (county). In the Ming Dynasty, Zhu Jing, the governor of Zhujing, repaired the Dachonghe (namely Yalong River) cable bridge, under the heading "The Ancient Road of Intercalary Salt", carved on the 
stone wall beside the road.Yanyuan, the capital of salt, iron and gold, has a long history. The horizontal axis of the region-"Lepidium Ancient Road" is not only a commercial road, but also a link between different regions and different national cultures, that is, a corridor and hub for national cultural activities. The historical records contain many ethnic groups that lived in Qidi, "Minorities have made significant contributions to the development of Yanyuan Salt Industry"[4] such as: Qiyi, Yueyu Qiang yak species, white wolf, Mohuiyi, Dao, Kunming, Moxie, etc., most of them are ancient Diqiang ethnic groups. Up to now, the ancient salt roads and areas of Leiyan are still the center of settlement of the Naxi people and the former Mosuo people who have ethnic origins with the ancient $\mathrm{Zi}$ people. Other ethnic groups include Yi, Lisu, Pumi, Tibetan, Mongolian, Bai, Miao, Dai, etc. The ancient road zone is the intersection of various elements such as environment, resources, nationalities, economy and culture. The intercalated Yandang Road serves as the throat of ancient Shu-Yun transportation. It passes through the southwest to Xi'er (Dali) and plays an important historical role as an economic and cultural corridor between Sichuan, Yunnan and Tibet. The "Lead Salt Ancient Road" is a supply line to maintain human survival. The ancient towns and villages on the ancient road are important stations. "Lead salt ancient road" contributed to the formation of my country's important cultural sedimentary zone. The "Lepidium Ancient Road" is distributed in the narrow mountains, canyons and cliffs of the Liangshan Mountains. Transport through "caravan". It is an important economic lifeline and cultural transmission route for various nationalities. The so-called "the two mountains face each other with thousands of roads, and Wancheng passed by the peak" is a portrayal of the carriage transportation. Among them, the horse gangs on the banks of Lugu Lake, formerly known as the Mosuo people, have long been famous, and their footprints cover Sichuan, Yunnan and Tibet, as far as Myanmar, India and other places. The Leiyan Ancient Road is divided into main lines and branch lines. The main line starts from today's Xichang Horse Road and reaches Lijiang via Yanyuan and Ninglang. Starting from Xichang Road (the place where the horses of various roads gather), cross the Anning River to the west, pass the Hexi, cross the Mopan Mountain of the Yak Mountain, enter the salt source, go down to the Chonghe Pass, cross the Yalong River, pass the Meizibao (Zhu Gui) along the canyon In this question), Lumabao, Pingchuan. Go up the small mountain, go down the mountain through the Acropolis, Yanyuan City, and arrive at the White Salt Well (there is an ancient salt pond). The whole journey is about 300 miles. In addition, there is a middle section of Bailang Line (from Baiyanjing to Ninglang County, Yunnan Province), which covers about 450 miles. The last section of the Lili Line (Ninglang to Lijiang) is about 450 miles. There is another road from Yanyuan to Lijiang, and the Baiyong Line (from Baiyanjing to Ninglang County, Yongning) is about 1,000 miles in length. The branch lines of the intercalated Yanyan Road mainly include: Baimu Line, Muyong Line, Yanpu Line, Liangyan Line, Yanlu Line, etc. In addition to running through the Hengduan
Mountains, the intercalated salt road must also pass through the Jinsha River, Yalong River and other river valleys. The bridges on the ancient roads include vine bridges, wooden bridges and stone bridges. The Fuji Bridge is also called the "Sasa Bridge". The "pile pavement bridge" of Caohai Lake in Lugu Lake is more representative today. The "open base bridge" of Yongning Stone Bridge is said to have been built by Kublai Khan's garrison at the sun, moon and time, so he is very famous. The River Carrier of the Leiyan Ancient Road.There are more than a dozen important ferries, and there are five important ferries along the Jinsha River at the junction of Ninglang County and Lijiang. The delivery vehicles include skin pouches, kayaks and wooden boats. The residents of Lugu Lake at the border of Sichuan and Yunnan still use wooden troughs. Nodes on the "Lead Salt Ancient Road"-Formation of Settlement.

\subsection{The Leiyan Ancient Road is also a golden channel.}

"The rich salt industry and other cultures in Yanyuan provide very important information for the study of the relationship between people and the land."[5]Yanyuan is famous for its rich gold production. Therefore, it is natural that some people associate "Jinsheng Lishui" with " Intercalary Salt Ancient Road". For example, Zhu Gui also inscribed the words "Jinsheng Lishui" while inscribed "The Ancient Road of Intercalary Salt". The Italian traveler Marco Polo's "The History of Marco Polo" states: At the beginning of the Yuan Dynasty, the capital built "to the currency it uses, there are gold bars, and the value of the case is measured." In its heyday, there were 30,000 workers and more than 100 Nissan gold." In the first year of Xuantong, he once got a natural gold nugget weighing 31 pounds, and then took a corner (weight 103 two) to display at the Panama Expo. It won the Panama Expo World Gold Award (Literary history of Yanyuan has a more detailed description)

\subsection{Runyan Ancient Road is an important "cultural route".}

However, the cultural heritage related to it is facing the situation of endangered and accelerated disappearance. To this end, it is hoped that from the perspective of "cultural routes", it will unite with relevant departments to declare the Runyan Ancient Road as a national key cultural relics protection unit, start the Runyan Ancient Road protection plan as soon as possible, and promote the effective protection of linear cultural heritage across regions. Protect the rich cultural heritage along the Sichuan-Yangtze Road from the perspective of cultural routes. Through the transportation route of salt on the ancient salt running road, salt transportation and cultural heritage, the preservation status of ancient towns, ancient streets, ancient villages and ancient salt roads have an overall grasp and understanding. 


\section{CONCLUSION}

"Lianyan Ancient Road" is not only a unique multi-ethnic cultural corridor, but also a four-in-one cultural route- - Golden Route", "Southern Silk Road" and "Old Tea Horse Road". "Integrated tourism along the ancient salt road, cluster tourism to explore ancient ruins, hilly tourism with local characteristics" [6] "Regional cultural tourism, rural tourism development and new rural construction" [7] To achieve a research on Ancient Salt Road Tourism Development project, multi-party beneficial effects. It not only has rich material and non-material cultural connotations, but also has beautiful natural scenery along the way. If the "Leiyan Ancient Road" is the main line of tourism, the scenic spots in the area and the beautiful settlements along the way will be established. Tourism industry economy where natural landscape and human landscape coexist. The protection of the ancient salt road has a long way to go and requires a lot of clue mining and data search. If we do not carry out systematic investigation and research on the tangible and intangible cultural heritage distributed on this cultural route, establish data files, determine key targets and formulate protection measures, I am afraid that we can only infer conjectures in historical ruins in the future. Regarding the in-depth development of ancient salt road tourism resources, a comprehensive assessment should be made to determine the advantages, disadvantages, opportunities, and threats [8]. In this way, the results obtained will be fully planned.

\section{ACKNOWLEDGMENT}

This research was financially supported by the Sichuan Provincial Department of Education and China Salt Culture Research Center Social Science.

Fund in 2015(Project Number: YWHY15-02) Phased results.

\section{REFERENCES}

[1] "Yanyuan County Annals" editorial committee. "Yanyuan County Annals" [M] Chengdu: Sichuan Nationalities Publishing House. 2000. pp. 1-1228

[2] Fanying Zeng; the connotation and characteristics of salt culture [J]; Journal of Sichuan University of Science and Technology (Social Science Edition); 2006(01). pp.47-52

[3] Shou Chen, Pei Songzhi's Note. The Three Kingdoms, Shu Zhi, Zhang Yi Zhuan [M]. Zhonghua Book Company, 1982.

[4] Shaoming Li. Contribution of ethnic minorities to the development of Yanyuan Salt Industry [A]. Collection of
Bashu National History [C]. Sichuan People's Publishing House, 2004.6.

[5] Sichuan Chengdu Archaeological Research Institute/Sichuan Liangshan Prefecture Museum Archaeological Investigation of Ancient Salt Industry and Culture in Yanyuan County, Sichuan [J] RELICS FROM SOUTH Southern Cultural Relics, 2011. pp.120-128

[6] Qingnan Deng.Salt Tourism Resources "In-Depth Tour" Integrated Thinking "Journal of Chengdu University of Technology" 2013(03) pp.18-21,36

[7] Yanqun Liu. Research on Ancient Salt Road Tourism Development and New Countryside Construction in Fubao Town, Sichuan Province, Journal of Sichuan University of Science and Technology: Social Science Edition, 2007(05) pp. $15-18$

[8] Yanqun Liu. SWOT analysis of the deep development of ancient salt road tourism resources in the Sichuan-Qiangyu-Chongqing Ecological Zone. Journal of Sichuan University of Science and Technology: Social Science Edition 2010(06) pp.20-23 